www.jmscr.igmpublication.org

Impact Factor 5.244

Index Copernicus Value: 83.27

ISSN (e)-2347-176x ISSN (p) 2455-0450

crossref DOI:_https://dx.doi.org/10.18535/jmscr/v4i11.22

Journal Of Medical Science And Clinical Research

\title{
Comparison between Functional Outcome of Intertrochanteric Fractures treated with Trochanteric Fixation Nail versus short Proximal Femoral Nail
}

Authors

\section{Dr Anandsrinivas A.Sowlee ${ }^{1}$, Dr R.Neelakrishnan², Dr V.Barathiselvan ${ }^{3}$, Dr A.T.Shanmuga Raja ${ }^{4}$, Dr V. Manooj Kumar ${ }^{5}$}

${ }^{* 1}$ Postgraduate in Orthopaedics, Rajah Muthiah Medical College \& Hospital, Annamalai University

${ }^{2}$ Professor of Orthopaedics, Rajah Muthiah Medical College \& Hospital, Annamalai University

${ }^{3}$ Senior Resident in Orthopaedics, Rajah Muthiah Medical College \& Hospital, Annamalai University

${ }^{4,5}$ Lecturer, Department of Orthopaedics, Rajah Muthiah Medical College \& Hospital, Annamalai University

\section{ABSTRACT}

Introduction: Intertrochanteric fractures are one of the most common fractures of the hip and have been recognized since the time of Hippocrates. The incidence of intertrochanteric fracture is rising because of increasing number of senior citizens with osteoporosis and also the increasing number of road traffic accidents. For stable intertrochanteric fractures dynamic hip screw was accepted as the gold standard. For unstable fractures intramedullary has been preferred recently. In this study we look to compare two types of intramedullary nails for unstable intertrochanteric fracture.

Aim of the Study- To compare the functional outcome of Intertrochanteric fractures treated with Trochanteric fixation nail versus Short proximal femoral nail.

Materials \& Methods- A prospective study done at the Department of Orthopaedics, Rajah Muthiah Medical College \& Hospital, Annamalai University, Chidambaram. Patient with Intertrochanteric fractures were treated with TFN and short PFN. Follow up was done at regular intervals for a period of 18 months.

Results \& Conclusion- During the period of study, fifty patients with unstable Intertrochanteric fracture were admitted. Out of which 30 patients were treated with TFN and 20 patients were treated with short PFN. Average age of patients was 65.07 years for patients treated with TFN and 68.50 years for patients treated with PFN.Overall mean time of radiological fracture union was 15 weeks (range 13-18). Mean hospital stay was 13 days (range 12 to 18 days).Average Modified Harris Hip Score was 88.25 for patients treated with TFN and 89.25 for patients treated with PFN. In our study, Patients with Unstable intertrochanteric fracture treated with TFN \& PFN had results that were comparable with each other but the difference was that when the fracture was extending below lesser trochanter trochanteric fixation nail could not be used.

Key words: Intertrochanteric fracture, trochanteric fixation nail, short proximal femoral nail, outcome.

\section{INTRODUCTION}

Intertrochanteric fractures are one of the most common fractures of the hip and have been recognized since the time of Hippocrates. Aitken suggested that degree of osteoporosis in fracture, influences fracture type ${ }^{1}$. The incidence of intertrochanteric fracture is rising because of increasing number of senior citizens with osteoporosis and also the increasing number of road traffic accidents. Gallagher et al suggested 
that, with increase in the life expectancy, the incidence of Intertrochanteric fractures has sharply risen among the geriatric population ${ }^{2}$ especially in the elderly with osteoporotic bones, usually due to low-energy trauma like simple falls. In the younger age group, where unstable Intertrochanteric fractures are more common, the cause is usually high-energy trauma like road traffic accidents. In India the incidence is estimated to double by 2040 .

Unstable Intertrochanteric fractures are those where there is poor contact between fracture fragments, especially medial and posterior cortical displacement, comminution or a fracture pattern such that the weight bearing forces tend to displace the fracture further or a reverse oblique type. It is universally agreed that the treatment of unstable intertrochanteric fractures is stable internal fixation as early as possible. Treatment goals for patients with unstable intertrochanteric fractures include early rehabilitation, restoration of the anatomic alignment of the proximal part of femur and maintenance of the fracture reduction. Stable intertrochanteric fractures are commonly treated with Dynamic hip screw (DHS) fixation. However, despite many methods, there has been no gold-standard treatment for unstable intertrochanteric fractures. Generally intramedullary nail has been preferred for unstable fractures. In this study we aim at comparing the functional outcome of intramedullary nails of two different length, trochanteric fixation nail $(180 \mathrm{~mm})$ versus proximal femoral nail $(250 \mathrm{~mm})$.

\section{MATERIALS AND METHODOLOGY}

A prospective study was conducted, the data for this study was collected from the patient admitted to Rajah Muthiah Medical College and Hospital, Annamalai University, Chidambaram, diagnosed to have Intertrochanteric Femur fracture, were treated surgically using trochanteric fixation nail and short proximal femoral nail during the period JUNE 2014 to AUGUST 2016. The clinical and radiological outcome was assessed and recorded. The ethical committee clearance was obtained from the institution. Inclusion Criteria was 1) Patients with intertrochanteric fractures aged 30 years and above, 2) All types of intertrochanteric fractures(especially those of osteoporotic \& grossly comminuted) treated with intramedullary nail, 3) Both males \& females, 4) No specific duration of illness, 5) adequate quality preoperative, immediate postoperative, atleast one set of adequate quality postoperative radiographs. Exclusion Criteria 1) Previous surgery of the proximal femur, 2) patients with pathological fractures other than osteoporosis, 3) Patients managed conservatively for other medical reasons, 4) Ongoing chemotherapy or irradiation treatment due to malignancy, 5) Patients who are not able to give consent were excluded from the study. If the fracture was not extending below lesser trochanter the patients were treated with Trochanteric fixation nail. If the fracture line extended below lesser trochanter proximal femoral nail was used.

Both the implants were made up of a stainless steel 316L type. The system consists of cannulated nail, cannulated hip screws of sizes 8 millimetres and 6.4 millimetres and locking bolts (4.9 millimetres). There is a locking mechanism in the upper part of the nail to control the rotation of the hip screw. The proximal diameter of the nail is thirteen millimetres. The size varies from nine to twelve millimetres. All nails have an anatomical valgus angle of six degrees. All parts of the nail are cannulated allowing insertion over guide wire. The angle between the nail and hip screws are available in 130 and 135 degrees. In the nail, there are two holes distally one each ofor static and dynamic locking. The locking bolts have a diameter of 4.9 millimetres. The length of nail used in TFN was $180 \mathrm{~mm}$. length of the nail used in PFN was $250 \mathrm{~mm}$

All the patients were put on fracture table and close reduction was done. When the fracture reduction was unacceptable, as determined by the surgeon, open reduction was done. Thus fracture reduction is the most important step prior to the fixation. Implants were placed and compression of the fracture was performed. Two Cephalomed- 
ullary screws were inserted with one or two distal screw as deemed by the surgeon.

The tip apex-distance was measured accurately prior to the placement of the Cephalomedullary screws. The distance was calculated in both AP \& lateral views. The adequacy of reduction of the posteromedial calcar was determined using both $\mathrm{AP}$ and lateral radiographs ${ }^{5}$. Initial radiographs were classified according the AO system and further sub-classified into unstable fractures (31A2.2, 31-A2.3, 31-A3.1, 31-A3.2, and 31-A3.3).

Post-operatively early mobilization was begun within limits of pain tolerance. Active, assisted and active range of motion exercises proved to be valuable adjuvant for achieving good range of motion. All patients were advised partial weight

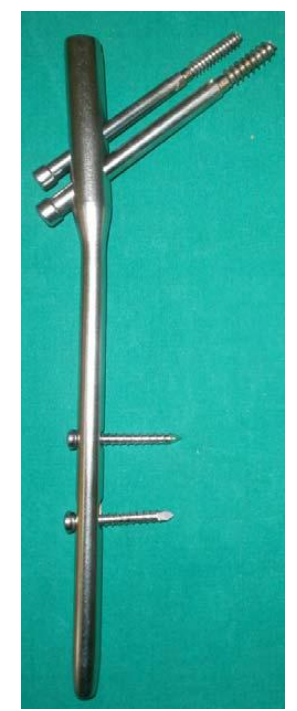

Proximal Femoral nail

\section{RESULTS}

During the period of study a total of 50 cases with intertrochanteric fracture were received. Twenty cases were treated with PFN and the remaining thirty cases were treated with TFN and patients were followed up at three months, six months, twelve \& eighteen month's intervals.

Average age of patients was 65.07 years for patients treated with TFN and 68.50 years for patients treated with PFN. Out of the 30 patients treated with TFN, 12 were male and 18 were female with right hip involvement in 17 patients and left hip in 13 patients. Out of the 20 patients treated with PFN, 7 were male and 12 were bearing with a walker for a period of six to eight weeks. Patients were allowed full weight bearing after radiological evidence of fracture union. Radiographs were taken at regular intervals and evaluated for fracture healing alignment, screw breakage or screw back-out, cut-out, Varus malunion collapse. Clinical union was defined as a painless fracture site during full weight bearing. Radiographic union was defined as bridging trabeculations across the fracture line on two orthogonal views in the absence of migration, loosening or breakage of hardware. Cases were followed up until eighteen months. Functional assessment of patients was done using Modified Harris Hip Scoring system.

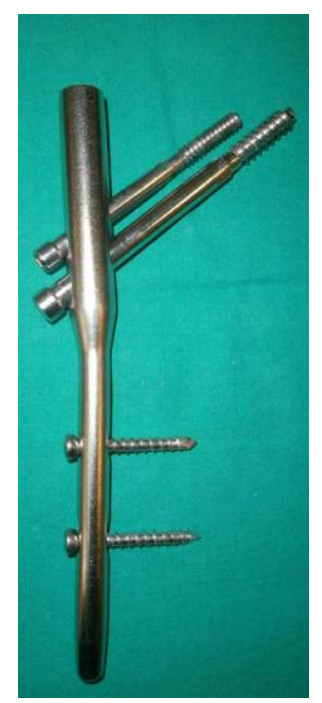

Trochanteric Fixation nail.

female, with right hip involvement in 10 cases and left hip in 10 cases. Average trauma surgery interval was 8 days (range 2 to 15 days). The average surgical time was 67 minutes (range 30 to 95 min).Among patients treated with TFN closed reduction was done in 26 patients whereas 4 patients required open reduction. Among patients treated with PFN, Closed reduction was achieved in 18 patients and open reduction in 2 patients. Average blood loss was $165 \mathrm{ml}$ (range 130 to $350 \mathrm{ml}$ ) Average hospital stay was 15 days (range 13 to 18 days). Partial weight bearing was achieved in mean 5 days (range 3 to 9 days). Full weight bearing was achieved after 50 days (41 to 
57 days). The Average radiological union was 15 weeks (12-18 weeks), Average Modified Harris Hip Score was 88.25 for patients treated with TFN and 89.25 for patients treated with PFN. The average neck shaft angle was 138 degrees (range 130- 145 degrees). In our series, among patients treated with TFN, three patients had Varus collapse, one patient had backing out of
Cephalomedullary screws due to poor purchase in head and one patient had significant shortening of $3 \mathrm{~cm}$ who was treated with sole raise shoes. Among patients treated with PFN two patients had varus collapse and two patients had anterior thigh pain which was not seen in patient treated with TFN.

Table 1 Results

\begin{tabular}{|l|c|c|}
\hline & TFN & PFN \\
\hline Number & 30 & 20 \\
\hline Age & 65.07 & 68.50 \\
\hline Sex (Male: Female) & $12: 18$ & $7: 13$ \\
\hline Side (Right: Left) & $17: 13$ & $10: 10$ \\
\hline Reduction (Closed : Open) & $26: 4$ & $18: 2$ \\
\hline Modified Harris Hip Score & 88.25 & 89.50 \\
\hline
\end{tabular}

Table 2 fracture pattern

\begin{tabular}{|l|c|c|}
\hline Type of fracture & No. of patients (TFN) & No. of Patients (PFN) \\
\hline $31-\mathrm{A} 2.1$ & 6 & 5 \\
\hline $31-\mathrm{A} 2.2$ & 12 & 4 \\
\hline $31-\mathrm{A} 2.3$ & 8 & 6 \\
\hline $31-\mathrm{A} 3.1$ & 2 & 2 \\
\hline $31-\mathrm{A} 3.2$ & 1 & 2 \\
\hline $31-\mathrm{A} 3.3$ & 1 & 1 \\
\hline
\end{tabular}

Table 3 Modified Harris Hip Score

\begin{tabular}{|l|c|c|}
\hline Score & No of Patients (TFN) & No. of Patients (PFN) \\
\hline Excellent (more than 90) & 7 & 6 \\
\hline Good (81-90) & 18 & 12 \\
\hline Fair (71-80) & 5 & 2 \\
\hline Poor (less than 70) & 0 & 0 \\
\hline
\end{tabular}

Table 4 Complications

\begin{tabular}{|l|c|c|}
\hline & TFN & PFN \\
\hline Post-operative Infection & 0 & 0 \\
\hline Varus collapse & 3 & 2 \\
\hline Screw backing out (reverse migration) & 1 & 0 \\
\hline Significant shortening (> 2cm) & 1 & 0 \\
\hline Non union & 0 & 0 \\
\hline Sciatic nerve palsy & 0 & 0 \\
\hline Anterior thigh pain & 0 & 2 \\
\hline
\end{tabular}




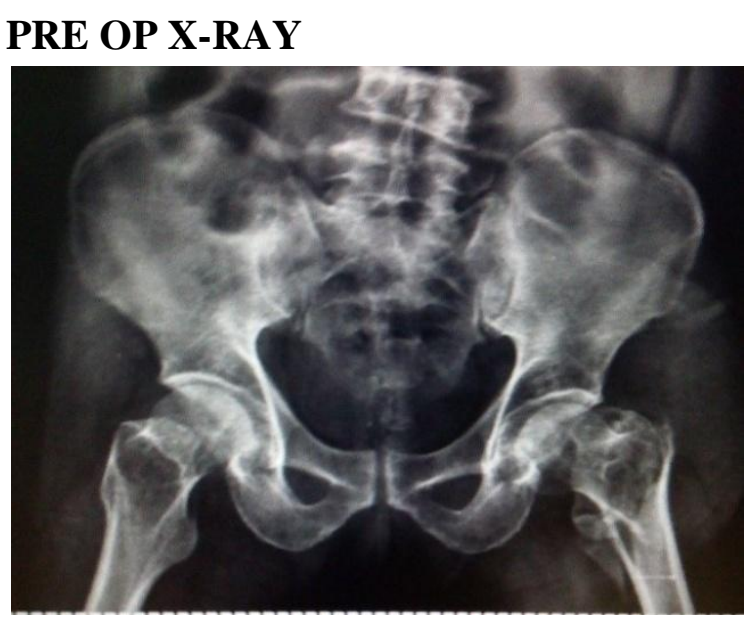

PRE OP X-RAY

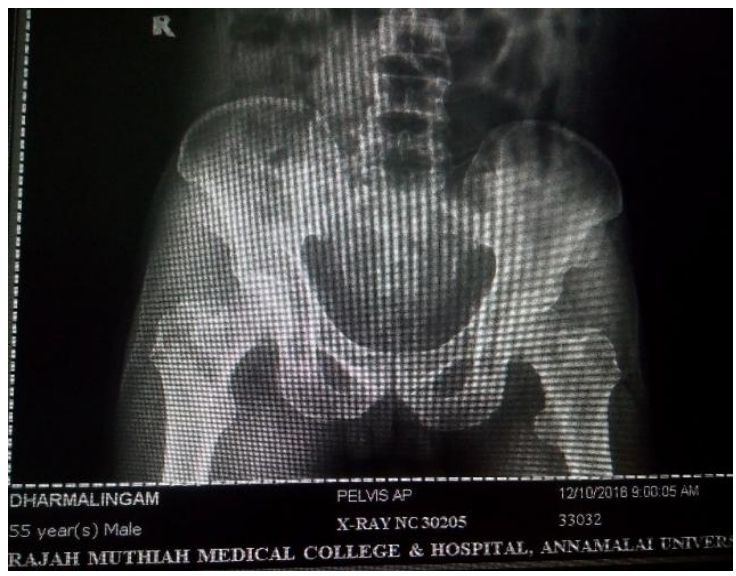

\section{DISCUSSION}

Intertrochanteric fractures in the elderly pose certain special problems. In this age group the fracture configuration is generally comminuted with presence of extensive osteoporosis. There is problem with correct and accurate placement of the implant and hold of the implant. So if the fixation is not stable, prolonged immobilization may be required to achieve complete union. On the other hand there is a need for rapid weight bearing and mobilization of this group of patients as they are generally medically compromised due to age and associated diseases.

Anthropometric measurements of proximal femur in Indian population is smaller than western population. So there appeared a need of design suitable for Indian Population. Egol KA, Chang EY, Cvitkovic J, Kummer FJ, Koval KJ ${ }^{20}$ (2004) did a study on the mismatch of current intramedullary nails with the anterior bow of the femur. They inferred that Intra-operative complications such as splintering and
POST OP X-RAY (treated with TFN)

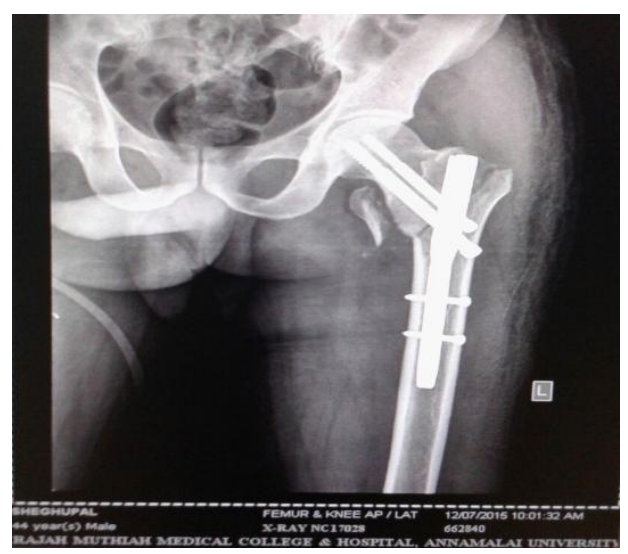

POST OP X-RAY (treated with PFN)

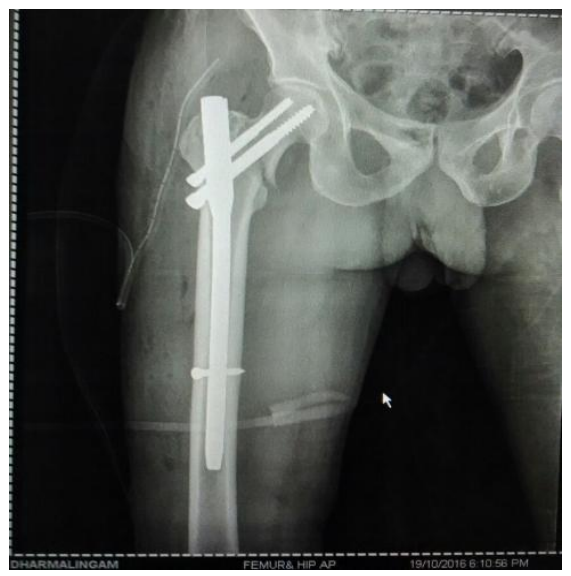

fractures are due to oversized implants that are manufactured according to western population parameters. In India, the proximal femoral nail is available with a length of $240-250 \mathrm{~mm}$. It crosses the middiaphysis of the femur. This may give rise to intra-operative femoral shaft fractures and thigh pain, because the implant touches the anterior cortex of the femur.

Modification of the gamma nail by reducing its diameter and length has been performed in the Chinese population. Hence complications such as splintering and fractures due to oversized implants can be avoided by using implants designed specifically for the relatively small Asian femur.

The TFN was designed for the Asian population keeping all these considerations in mind. Currently, there is only one study reported till date, of the TFN for treating intertrochanteric fractures in Asians. Currently there is only one study with TFN. 
Gadegone WM, Salphale YS $^{21}$ (April 2010) reviewed outcomes of 100 Asian patients who underwent trochanteric femoral nailing for stable and unstable intertrochanteric fractures. They concluded, that trochanteric fixation nail is a superior implant for stable and unstable intertrochanteric fractures in terms of operating time, surgical exposure, blood loss, and complications, especially for patients with relatively small femur.

Outcomes of treatment of intertrochanteric fractures depends on quality of bone, age of patient, general health, trauma surgery interval, and adequacy of treatment, comorbidities and stability of fixation $^{9,10,11}$.

TFN \& PFN acts as a buttress to prevent medialisation of the shaft and provides more efficient load transfer ${ }^{16}$. It is designed to provide linear intraoperative compression of head neck segment to shaft along with rotational stability which minimizes neck malunions, resulting in negligible complication rate ${ }^{17}$. It has been proved to be a superior implant compared to previous implants for stable and unstable intertrochanteric fractures in terms of operating time, surgical exposure, blood loss, and complication rates ${ }^{18}$. TFN reduces stress concentration at the tip and the smaller distal diameter may prevent femoral shaft fractures ${ }^{19}$. But the drawback was that when the fracture extended below the lesser trochanter PFN provided more stability than TFN.

When the fracture line was extending below lesser trochanter or when the lesser trochanter was present as a third fragment, the fracture was fixed with proximal femoral nail. But when the fracture was not involving lesser trochanter, the fracture was fixed with trochanteric fixation nail.

Since the trochanteric fixation nail is shorter in length than proximal femoral nail there was no need for intraoperative reaming and the incidence of anterior thigh pain was not seen but as the nail was shorter it did not give enough stability when the fracture was extending below lesser trochanter. Till now there are no studies involving comparison between TFN and PFN.

\section{CONCLUSION}

For unstable intertrochanteric fractures fixation is must. Fracture reduction is the key step of the surgery. Intramedullary nailing has shown to be effective in providing early mobilisation and weight bearing. When the fracture does not involve the lesser trochanter, TFN is as effective as PFN but when the fracture is extending below the lesser trochanter or the lesser trochanter is present as a separate fragment, the more ideal choice of implant is proximal femoral nail which is longer than trochanteric fixation nail. Since there are no previous studies comparing the outcome of TFN with short PFN. Still further studies with larger population is deemed necessary to say the efficacy.

\section{DISCLOSURE OF INTEREST}

The authors declare that they have no conflicts of interest concerning this article.

\section{REFERENCES}

1. Koval KJ, Aharonoff GB, Rokito AS, et al. Patients with femoral neck and intertrochanteric fractures. Are they the same? Clin Orthop Relat Res.1996; 330:166-172.

2. Grisso JA, Kelsey JI, Strom BL, and Chio GY. Risk factors for falls as a cause of hip fractures in women. New England journal of medicine. 1991; 324:1326-1331.

3. Meislin RJ, Zuckerman JD, Kummer FJ, et al. A biomechanical evaluation of the gamma nail. J Bone Joint Surg.1998; 70A: 239

4. Anchal Kumar. Femoral neck geometry and rationale of placement of the proximal femoral nail and its relation with fracture risk in the Indian population review of 120 cases. 2010: Gulmohar Hospital, Ranchi.

5. Fracture and dislocation compendium. Orthopaedic trauma association committee for coding and classification. J Orthop Trauma 1996;10(Suppl. 1):1-154. v-ix.

6. Baumgaertner MR, Curtin SL, Lindskog DM, Keggi JM. The value of the tip-apex 
distance in predicting failure of fixation of peritrochanteric fractures of the hip. J Bone Joint Surg Am 1995;77:1058 - 64.

7. Pervez H, Parker MJ, Vowler S. Prediction of fixation failure after sliding hip screw fixation. Injury 2004;35:994-8.

8. Yoshimine F, Latta LL, Milne EL. Sliding characteristics of compression hip screws in the intertrochanteric fracture: a clinical study. J Orthop Trauma 1993;7:348 — 53.

9. Kyle RF, Gustilo RB, Premer PF. Analysis of Six hundred and Twenty-two intertrochanteric Hip Fractures. J. Bone Joint Surg. 1979 March; 61-A: 216-21.

10. Dahl E. Mortality and life expectancy after hip fractures. Acta Orthop Scand. 1980 Feb; 51(1)163-70.

11. Kaufer H. Mechanics of the treatment of hip injuries. Clin Orthop Relat Res. 1980 Jan-Feb;146:53-61.

12. Grisso JA, Kelsey JI, Strom BL, and Chio GY. Risk factors for falls as a cause of hip fractures in women. New England journal of medicine. 1991; 324:1326-1331.

13. Ender J, Simon-Weidner R. Die Fixierung der trochanteren Bruchemitrundenelastischen Condylennageln. Actachir Austriaca 1970; 1: 40-42.

14. Cleas H, Broos P, Stappaerts K. Pertrochanteric Fractures in Elderly patient Treatment with Ender's nail, bladeplate or endoprosthesis? Injury. 1985; 16(4):26164.

15. Heyse-Moore G.H, MacEachen AC, and Jameson Evans DC. Treatment of trochanteric fractures of the femur. $\mathrm{J}$ Bone Joint Surg. 1983; 65-B: 262-267.

16. Morihara T, Arai Y,Tokugawa S, Fujita S, Chatani K, Kubo T. Proximal femoral nail for treatment of trochanteric femoral fractures. Journal of Orthopaedic Surgery 2007; 15(3):273-7.

17. Ruecker AH, Rupprecht M, Gruber M, Gebauer M, Barvencik F, Briem D, Rueger JM: The treatment of intertrochanteric fractures: results using an intramedullary nail with integrated cephalocervical screws and linear compression. J Orthop Trauma. 2009;23(1):22-30.

18. Gill JB, Jensen L, Chin PC, Rafiei P, Reddy K, Schutt RC Jr: Intertrochanteric hip fractures treated with the trochanteric fixation nail and sliding hip screw. J SurgOrthop Adv. 2007; 16(2):62-6.

19. Bienkowski P, Reindl R, Berry GK, Iakoub E, HarveyEJ: A new intramedullary nail device for the treatment of intertrochanteric hip fractures: Perioperative experience. J Trauma. 2006; 61(6): 1458-62.

20. Egol KA, Chang EY, Cvitkovic J, Kummer FJ, Koval KJ. Mismatch of current intramedullary nails with the anterior bow of the femur. $\mathrm{J}$ OrthopTrauma 2004;18:410-5.

21. Gadegone WM, Salphale YS. Short Proximal Femoral Nail Fixation for trochanteric Fractures J Orthop Surg (Hong Kong). 2010 Apr; 18(1):39-44. 